Jurnal Pemberdayaan: Publikasi Hasil Pengabdian kepada Masyarakat

Vol. 2, No. 3, Desember 2018, Hal. 519-524

ISSN: 2088 4559; e-ISSN: XXXX-XXXX

DOI:

\title{
PEMBERDAYAAN MASYARAKAT DUSUN JODOG, KARANGASEM, KADISORO, DESA GILANGHARJO, PANDAK, BANTUL DALAM PENGOLAHAN SAMPAH
}

\author{
Iis Wahyuningsih ${ }^{1}$, Aji Setya Bakti ${ }^{2}$, Indriyani Fransiska ${ }^{3}$, Hensi Oktavia ${ }^{4}$ \\ 1,2,3,4 Universitas Ahmad Dahlan, Jalan Kapas, No 9, Semaki Yogyakarta 55166 \\ Email: iis.wahyuningsih@pharm.uad.ac.id
}

\begin{abstract}
ABSTRAK
Salah satu permasalahan di Dusun Jodog, Karangasem dan Kadisoro Desa Gilangharjo, kecamatan Pandak Kabupaten Bantul adalah kurangnya pengetahuan masyarakat tentang kesehatan lingkungan terutama cara mengelola sampah dengan baik dan benar. Maka program Kuliah Kerja Nyata (KKN) Universitas Ahmad Dahlan (UAD) ini bertujuan memberdayakan masyarakat untuk dapat mengelola sampah dengan baik dan benar. Metode pelaksanaan program KKN meliputi: pendidikan masyarakat yang berbentuk seperti penyuluhan serta praktek langsung. Dampak dari kegiatan KKN ini adalah : 1) peningkatan pengetahuan masyarakat padukuhan Jodog, Karangasem dan Kadisoro dalam mengelola sampah, 2) masyarakat padukuhan Jodog, Karangasem dan Kadisoro dapat memilah sampah organic dan anorganic, dapat membuat kompos, dapat membuat pupuk organik cair, dan dapat membuat kerajinan dari barang bekas.
\end{abstract}

Kata kunci : pemberdayaan, masyarakat, sampah

\begin{abstract}
One of the problems in Jodog, Karangasem and Kadisoro Hamlet, Gilangharjo Village, Pandak Subdistrict, Bantul Regency is the lack of public knowledge about environmental health, especially on how to manage waste properly and correctly. So the UAD KKN program aims to empower the community to be able to manage waste properly and correctly. Methods of implementing the KKN program include: community education in the form of counseling and direct practice. The impact of the KKN activities are: 1) increasing knowledge of the people of Jodog, Karangasem and Kadisoro in managing waste, 2) the people of Jodog, Karangasem and Kadisoro can sort organic and inorganic waste, can make compost, can make liquid organic fertilizer, also could make handicrafts from an already used goods.
\end{abstract}

Keywords: empowerment, community, waste 


\section{PENDAHULUAN}

Dusun Jodog, Karangasem dan Kadisoro merupakan tiga dusun dari lima belas dusun di Desa Gilangharjo. Keadaan tanah di ketiga dusun tersebut terbilang subur dengan air cukup memadai. Masyarakat di dusun ini memiliki akses yang mudah untuk bercocok tanam dan sebagian besar masyarakat adalah bekerja sebagai petani.

Di tiga dusun tersebut, pengolahan sampah masih dilakukan secara tradisonal oleh masing - masing anggota keluarga. Umumnya masyarakat menumpuk sampah di pekarangan rumah, dibuang ke sungai atau dibakar. Volume sampah di tiga dusun tersebut mencapai kira - kira $2 \mathrm{~kg}$ per KK. Di daerah ini belum ada kegiatan yang diwujudkan untuk mengurangi dampak sampah terhadap kesehatan, lingkungan, atau keindahan. Lingkungan menjadi terlihat kotor yang berpotensi menjadi tempat berkembangnya organisme patogen yang berbahaya bagi kesehatan. Sampah yang membusuk menimbulkan bau yang tidak sedap. Dampak selanjutnya dapat menimbulkan pencemaran sumur, sungai maupun air tanah. Sampah yang tercecer tidak pada tempatnya dapat menyumbat saluran drainase sehingga dapat menimbulkan bahaya banjir.

Sampah sebenarnya dapat bernilai jual tinggi jika dikelola dengan benar. Tujuan jangka panjang kegiatan ini adalah pemberdayaan masyarakat terhadap permasalahan sampah, yang pada akhirnya masyarakat dapat berperan aktif dalam menciptakan lingkungan tempat tinggal yang bersih dan sehat. Tujuan jangka pendek program ini adalah perbaikan sistem pengolahan sampah, pemberdayaan masyarakat melalui pengelolaan produk hasil daur ulang, sehingga dapat menciptakan produk olahan sampah yang memiliki manfaat di masyarakat.

\section{METODE}

Untuk mencapai tujuan yang diharapkan, program KKN UAD yang termasuk periode regular 65 ini, dilakukan di tiga dusun tersebut dengan memberdayakan masyarakat melalui pendidikan masyarakat dan praktek langsung yang dilakukan selama 1 bulan, tanggal 25 Januari-25 Februari 2018. Ringkasan metode pelaksanaan beserta jam kerja efektif mahasiswa (JKEM) tersaji pada table 1. 
Tabel 1. Metode, Kegiatan, Alokasi Waktu dan keterlibatan mahasiswa

\begin{tabular}{|c|c|l|c|c|}
\hline No & Metode & Kegiatan & $\begin{array}{c}\text { Alokasi Waktu } \\
\text { (menit) }\end{array}$ & $\begin{array}{c}\text { Jumlah } \\
\text { mahasiswa } \\
\text { yang terlibat }\end{array}$ \\
\hline 1 & $\begin{array}{l}\text { Pendidikan } \\
\text { masyarakat }\end{array}$ & $\begin{array}{l}\text { Menyelenggarakan } \\
\text { penyuluhan tentang cara } \\
\text { pengolahan sampah yang baik } \\
\text { dan benar }\end{array}$ & $1 \times 100 "$ & 27 \\
\cline { 3 - 5 } & \multirow{2}{*}{2} & $\begin{array}{l}\text { Menyelenggarakan } \\
\text { penyuluhan pupuk kompos }\end{array}$ & $1 \times 100 "$ & 27 \\
\hline \multirow{2}{*}{\begin{tabular}{l} 
Praktek \\
\cline { 3 - 5 }
\end{tabular}} & $\begin{array}{l}\text { Pelatihan pengolahan sampah } \\
\text { pupuk kompos dan cair }\end{array}$ & $1 \times 100 "$ & 27 \\
\cline { 3 - 5 } & $\begin{array}{l}\text { Pelatihan Pembuatan } \\
\text { kerajinan tangan dari barang } \\
\text { bekas }\end{array}$ & $4 \times 100 "$ & 27 \\
\hline
\end{tabular}

\section{HASIL, PEMBAHASAN, DAN DAMPAK}

Sampah yang belum dikelola dengan baik akan menimbulkan berbagai permasalahan. Dalam jangka panjang, kebiasaan membuang sampah ke sungai dan membakar sampah di perkarangan rumah akan memberikan dampak negatif. Bau yang tidak sedap yang disebabkan oleh penumpukan sampah di perkarangan dan aliran sungai. Kebiasaan seperti ini akan dapat menyebababkan berbagai penyakit seperti malaria, diare, kolera, atau dapat pula menyebabkan gangguan pada kulit karena sungai di sekitar tempat kita telah tercemar.

Dalam upaya penanganannya pemerintah perlu mendorong kesadaran dan peran aktif masyarakat secara terus menerus dalam pelaksanaan pengelolaan sampah, karena pelestarian lingkungan adalah kewajiban kita semua yang berada pada lingkungan sosialnya. Untuk menghindari terjadinya hal-hal yang tidak diinginkan akibat sampah, harus ada kegiatan yang inovatif untuk memanfaatkan sampah tersebut agar dapat menghasilkan produk yang bermanfaat.

Sejauh ini peran masyarakat dalam pengelolaan sampah masih rendah, ada pula sebagian kecil masyarakat yang belum mau peduli terhadap masalah sampah di lingkungan tempat tinggalnya. Maka dibutuhkan suatu usaha untuk mengaktifkan peran masyarakat, baik dalam memberikan edukasi maupun dalam praktek kegiatan pengelolaan sampah secara 
langsung. Oleh karena itu diperlukan suatu usaha pemberdayaan masyarakat yang diharapkan dapat menjadi jalan untuk menggali potensi masyarakat dalam pengelolaan sampah di lingkungan masing-masing, seperti yang telah dilakukan oleh KKN UAD yang tersaji pada Gambar 1.

Berikut pelaksanaan program KKN UAD di padukuhan Jodog, Karangasem dan Kadisoro yang telah dilakukan:

1. Penyuluhan pengolahan sampah dan sedekah sampah

Kegiatan sedekah sampah diselenggarakan oleh KKN UAD yang dibantu oleh pemuda-pemudi. Kegiatan ini berupa pengumpulan barang bekas dari setiap warga. Kemudian hasil pemgumpulan barang bekas tersebut dikumpukan dan dijual kepada pengepul sampah, yang mana hasil dari penjualan barang bekas tersebut digunakan untuk pemakmuran masjid.

2. Pelatihan pupuk organic cair

Sasaran dari pelatihan pembuatan pupuk organik adalah masyarakat dan kelompok tani. Tujuan dari pelatihan ini adalah untuk memberi ketrampilan kepada masyarakat tentang bagaimana memanfaatkan sampah organik untuk dijadikan pupuk organic yang dengan harga yang ekonomis dan praktis. Pelatihan pupuk organik ini menggunakan bahan-bahan sisa sayur dan buah sehingga mudah didapatkan dan diaplikasikan.

3. Pelatihan pembuatan kompos.

Dilakukan pula pelatihan pengelolaan sampah organik. Melalui program recycle, sampah dari dedaunan dan sisa makanan, sayuran, dll. diproses untuk dijadikan kompos. Melalui pelatihan dan pendampingan, warga masyarakat didampingi untuk menghasilkan produk yang lebih bermanfaat. 


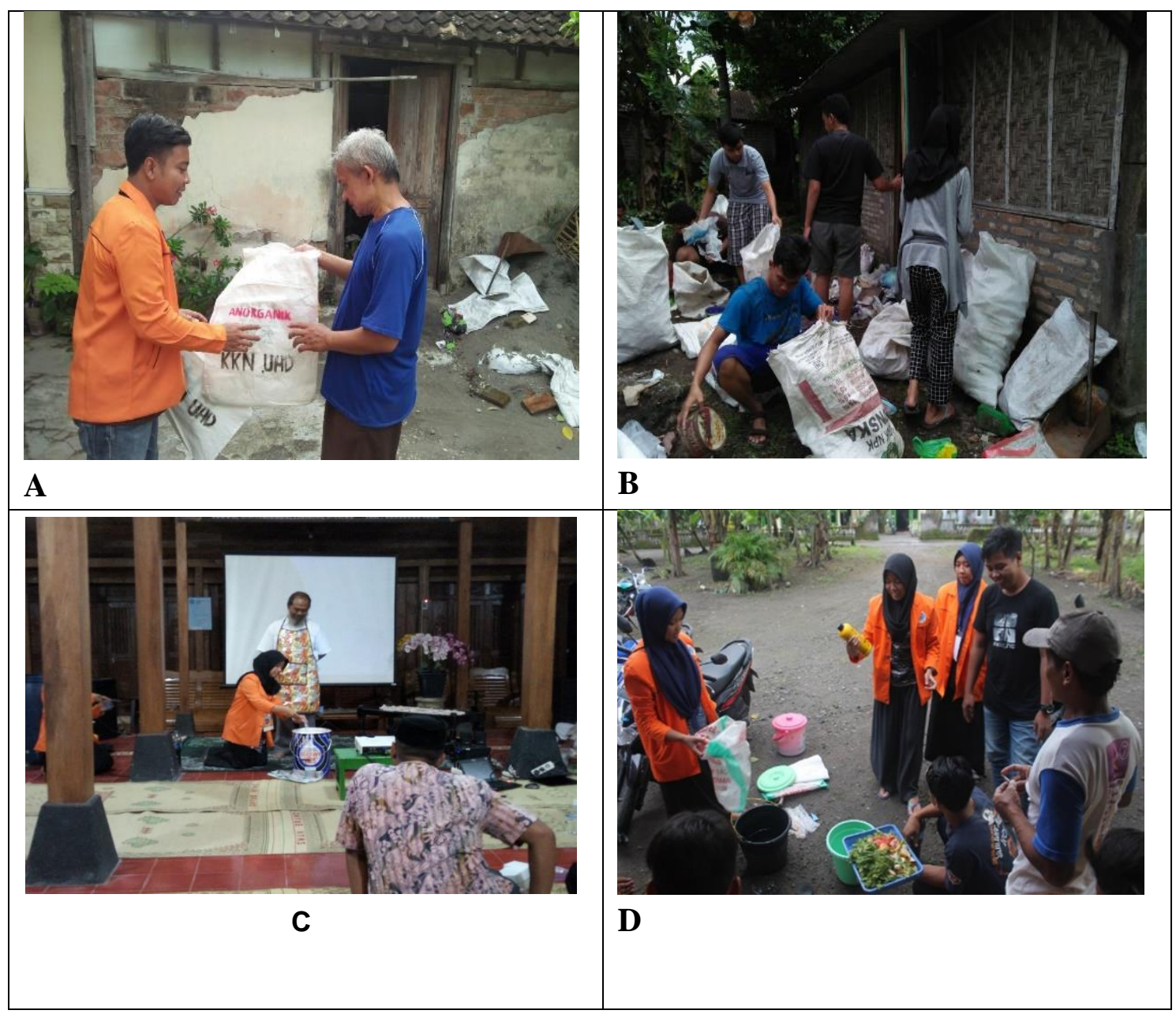

Gambar 1. A. Pembagian karung untuk pemilahan sampah, B. Praktek pemilahan sampah, C. Praktek pembuatan pupuk cair, D. Praktek pembuatan kompos

Menurut Anonim (2018) langkah-langkah mempersiapkan masyarakat dalam pemberdayaan pengelolaan sampah adalah :

1. Persiapan awal : Persiapan awal pada intinya merupakan upaya mencari cara pendekatan ke masyarakat agar pada saat mengusulkan rencana untuk merubah sesuatu tatanan yang sudah ada tidak menimbulkan gesekan sosial atau pertentangan.

2. Rencana Aksi Masyarakat adalah suatu tindakan untuk menciptakan perubahan dalam masyarakat yang folus pada kegiatan yang akan dilakukan, siapa yang melakukan dan bagaimana melakukannya, atau dengan kata lain menjelaskan apa yang diinginkan kelompok masyarakat untuk dijalankan dalam mencapai target pengelolaan sampah yang diinginkan.

3. Pembentukan forum masyarakat, yang direncanakan akan mengkoordinir pelaksanaan pemberdayaan masyarakat serta teknis pelaksanaan kegiatan pengelolaan sampah, mulai dari implementasi sampai pada tahap evaluasi dan pengawasan. Forum masyarakat juga berfungsi 
sebagai wadah untuk menampung aspirasi warga untuk kepentingan bersama dan mencari solusi bila timbul permasalahan.

4. Kegiatan tindak lanjut.

Menurut Anonim (2012) strategi peningkatan peran serta masyarakat dalam pengeloaan sampah adalah : 1) menyampaikan informasi, atau meneruskan informasi melalui media masa atau media social, 2) memberi penghargaan dan menghukum, bertujuan untuk mempengaruhi (kepercayaan, nilai, cara bertindak) masyarakat. Bila pemberian penghargaan belum berhasil, maka dilakukan hukuman untuk memaksa masyarakat berubah sikap, 3) mengadakan dialog.

\section{SIMPULAN}

Program KKN UAD dapat meningkatkan pemberdayaan masyarakat Dusun Jodog, Karangasem dan Kadisoro Desa Gilangharjo, Bantul dalam pengelolaan sampah.

\section{DAFTAR PUSTAKA}

https://docplayer.info/394439-Pedoman-pemberdayaan-masyarakat-dalam-pengelolaansampah.html, diakses 9 Januari 2018

https://jujubandung.wordpress.com/2012/06/02/peran-serta-masyarakat-dalam-pengelolaansampah, diakse 9 Januari 2018. 